Slavica

bruxellensia

\section{Slavica bruxellensia}

Revue polyphonique de littérature, culture et histoire

slaves

12 | 2016

Miniatures

\title{
Bolton J., Světy Disentu: Charta 77, The Plastic People of the Universe a česká kultura za komunismu
}

\section{Astrid Muls}

\section{(2) OpenEdition}

1 Journals

\section{Édition électronique}

URL : http://journals.openedition.org/slavica/1805

DOI : 10.4000/slavica.1805

ISSN : 2034-6395

\section{Éditeur}

Université libre de Bruxelles - ULB

Référence électronique

Astrid Muls, «Bolton J., Světy Disentu: Charta 77, The Plastic People of the Universe a česká kultura za komunismu », Slavica bruxellensia [En ligne], 12 | 2016, mis en ligne le, consulté le 25 septembre 2020. URL : http://journals.openedition.org/slavica/1805; DOI : https://doi.org/10.4000/slavica.1805

Ce document a été généré automatiquement le 25 septembre 2020.

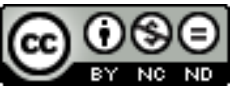

Les contenus de Slavica bruxellensia sont mis à disposition selon les termes de la Licence Creative Commons Attribution - Pas d'Utilisation Commerciale - Pas de Modification 3.0 France. 


\title{
Bolton J., Světy Disentu: Charta 77, The Plastic People of the Universe a česká kultura za komunismu
}

\author{
Astrid Muls
}

\section{RÉFÉRENCE}

Bolton J., Světy Disentu: Charta 77, The Plastic People of the Universe a česká kultura za komunismu, traduit par Petruška Šustrová, Nakladatelství Academia, Prague, 2015, 480 p.

1 C'est à la thématique de la dissidence en Tchécoslovaquie que Jonathan Bolton consacre son ouvrage Worlds of dissent: Charter 77, The Plastic People of the Universe, and Czech Culture under Communism ${ }^{1}$, paru en tchèque en 2015 sous le titre Světy Disentu. S'attaquant à des approches historiques unilatérales et au stéréotype d'une dissidence héroïque aux valeurs morales absolues, Bolton procède à une démystification et à une recomplexification de ce phénomène.

2 Affublés de l'appellation de dissidents par les productions journalistiques occidentales, ce n'est qu'avec réticence que les opposants tchécoslovaques commenceront à utiliser ce terme durant la seconde moitié des années 1970. Alors que l'initiative de la Charte 77, pétition appelant au respect des droits de l'homme, eut un écho retentissant à l'Ouest qui s'empressa d'ériger les Chartistes en héros, les autorités tchécoslovaques, quant à elles, adoptèrent immédiatement une politique de répression envers ceux-ci. Mettant en contraste l'interprétation édulcorée de l'Occident et la réalité de son quotidien, Bolton entreprend la réexploration de la dissidence à partir de ses problématiques internes.

3 Qu'était-ce, dans les faits, qu'être un dissident? Quel était le public de la dissidence? Était-ce une communauté fermée, réservée à l'élite intellectuelle et aux signataires de la Charte 77, ou était-elle effectivement ouverte à tous? Des questions épineuses que 
Bolton aborde en ravivant les débats qui animaient la communauté dissidente de l'époque à propos de son identité. Plutôt que de la définir strictement, l'auteur présente la dissidence comme fondée sur une identité paradoxale: étant à la fois une communauté délimitée et potentiellement ouverte à une infinité d'individus et en même temps une initiative morale et un espace d'action, la dissidence tchécoslovaque se mouvait constamment entre ces différents pôles qui la constituaient.

Tout en retraçant son histoire, Bolton reformule la dissidence en tant que diversité. En évitant de la limiter aux signataires de la Charte 77 et de la réduire à la visibilité de quelques-uns de ses membres, l'auteur met en avant la multitude d'individus et d'activités qui définissaient la communauté dissidente. Ainsi, à côté de figures emblématiques telles que Václav Havel ou Jan Patočka apparaissent des personnalités telles que Jan Vladislav, fondateur de l'édition samizdat Kvart, ou Ludvík Vaculík, écrivain et fondateur de l'édition samizdat Petlice.

Bolton consacre un chapitre entier à La Clef des songes (Český snár̆, 1980) de Vaculík, un récit à mi-chemin entre le journal et la nouvelle qui retrace la vie quotidienne de l'auteur de 1979 à 1980. À côté des documents «officiels » et des essais qui relatent les activités et les objectifs de la dissidence, Bolton insiste sur l'importance historique des productions littéraires écrites à la première personne. En plus d'apporter des témoignages sur ce qu'était la vie quotidienne des dissidents, ces écrits expriment la pluralité des opinions et des personnalités qui évoluaient au sein de l'opposition tchécoslovaque. C'est en cela que la dissidence peut être perçue comme un phénomène pluriel ; bien que mus par des idéaux moraux convergents, les membres de celle-ci n'en étaient pas moins des entités hétérogènes dont les réalités et les opinions divergeaient.

Un des intérêts majeurs de l'ouvrage de Bolton réside dans la pertinence de son approche du phénomène de la dissidence. Ne se bornant pas uniquement à autopsier ce phénomène en tant que tel, l'auteur s'intéresse également à la manière dont celui-ci s'est cristallisé dans l'histoire et dans la mémoire collective. Dans un souci d'objectivité qu'il ne cesse de réaffirmer tout au long de sa recherche, Bolton remet en question les interprétations classiques de la dissidence en s'efforçant de la replacer dans l'enchevêtrement de son contexte politique et sociologique. Parallèlement, l'auteurmet en exergue une multitude de pistes inexploitées, ce qui permet au lecteur d'appréhender la dissidence tchécoslovaque en tant que phénomène dont l'étude n'en est encore qu'à ses balbutiements. Worlds of dissent rouvre le dossier de la dissidence tchécoslovaque en lui donnant la possibilité de se déployer. Cet ouvrage constitue une invitation efficace à l'approfondissement d'un épisode historique encore largement inexploré.

\section{NOTES}

1. Bolton J., Worlds of Dissent: Charter 77, The Plastic People of the Universe, and Czech Culture under Communism, Harvard University Press, Cambridge, Massachusetts and London, England, 2012, 360 p. 


\section{AUTEURS}

\section{ASTRID MULS}

Etudiante en Master d'Europe centrale à l'Université libre de Bruxelles 